\title{
Photosynthetic activity and early growth of four Cacao genotypes as influenced by different shade regimes under West African dry and wet season conditions
}

Article

Published Version

Acheampong, K., Hadley, P. and Daymond, A. (2013) Photosynthetic activity and early growth of four Cacao genotypes as influenced by different shade regimes under West African dry and wet season conditions. Experimental Agriculture, 49 (1). pp. 31-42. ISSN 0014-4797 doi: https://doi.org/10.1017/S0014479712001007 Available at https://centaur.reading.ac.uk/31132/

It is advisable to refer to the publisher's version if you intend to cite from the work. See Guidance on citing.

To link to this article DOI: http://dx.doi.org/10.1017/S0014479712001007

Publisher: Cambridge University Press

All outputs in CentAUR are protected by Intellectual Property Rights law, including copyright law. Copyright and IPR is retained by the creators or other copyright holders. Terms and conditions for use of this material are defined in the End User Agreement. 


\section{www.reading.ac.uk/centaur}

\section{CentAUR}

Central Archive at the University of Reading

Reading's research outputs online 


\title{
PHOTOSYNTHETIC AGTIVITY AND EARLY GROWTH OF FOUR GAGAO GENOTYPES AS INFLUENGED BY DIFFERENT SHADE REGIMES UNDER WEST AFRIGAN DRY AND WET SEASON GONDITIONS
}

\author{
By K. ACHEAMPONG $\dagger$ ’, P. HADLEY $\ddagger$ and A. J. DAYMOND $\ddagger$ \\ $\dagger$ Cocoa Research Institute of Ghana, PO Box 8, Akim Tafo, Ghana, West Africa and $\ddagger$ School of \\ Agriculture, Policy and Development, The University of Reading, Whiteknights, Reading, RG6 \\ $6 A R, U K$
}

(Accepted 13 October 2012)

\author{
SUMMARY
}

\begin{abstract}
The physiological performance of four cacao clones was examined under three artificial shade regimes over the course of a year in Ghana. Plants under light shade had significantly higher photosynthetic rates in the rainy seasons whereas in the dry season there was a trend of higher photosynthetic rates under heavy shade. The results imply that during the wet seasons light was the main limiting factor to photosynthesis whereas in the dry season vapour pressure deficit was the major factor limiting photosynthesis through stomatal regulation. Leaf area was generally lower under heavier shade but the difference between shade treatments varied between clones. Such differences in leaf area allocation appeared to underlie genotypic differences in final biomass production in response to shade. The results suggest that shade for young cacao should be provided based on the current ambient environment and genotype.
\end{abstract}

\section{INTRODUCTION}

The use of shade trees is a common practice in the establishment of cacao (Theobroma cacao L.) (de Almeida and Valle, 2007; Raja Harun and Hardwick, 1988b). Gaining a better understanding of how light levels impact the early performance of cacao is an important component in optimising its growth during the establishment phase. Such knowledge is important because replanting of cacao is expected to become more challenging under predicted climate change scenarios, and yet this will be needed if the anticipated future demand for cocoa beans (International Cocoa Organization (ICCO), 2008) is to be met.

Cacao has a number of attributes that are typical of shade species. These include low photosynthetic rates (Daymond et al., 2011) and a high sensitivity to photoinhibitory stress (Galyuon et al., 1996a, b; Serrano and Biehl, 1996). There is a general view that shading (usually by other plants) is a requirement of young cacao plants to ameliorate physiological stress caused by high light intensities and to reduce evapotranspiration (Ahenkorah et al., 1974). However, there is still considerable inconsistency in what is considered to be the optimal shading levels for cacao. For example, whereas cacao is also known to have low light saturation levels of around $400 \mu \mathrm{mol} \mathrm{m}^{-2} \mathrm{~s}^{-1}$ (Daymond 
et al., 2011; Raja Harun and Hardwick, 1988a), studies conducted by Da Matta et al. (2001) and Rada et al. (2005) suggest that some cacao genotypes may show increasing photosynthetic rates as the photosynthetically active radiation (PAR) increases up to $750 \mu \mathrm{mol} \mathrm{m}^{-2} \mathrm{~s}^{-1}$. Furthermore, differences between genotypes in canopy attributes (e.g. size of canopy and amount of self-shading) will impact on their response to shade.

Since there is a defined dry season in West Africa where the bulk of the world's cacao is cultivated, it is also important to understand whether genotypic responses to different shade regimes vary across seasons. Moreover, there is a paucity of information on the extent of genotypic response to different shading regimes, particularly across seasons.

To address these questions, the study described here assesses the response to shade of four contrasting cacao clones (SCA 6, T 79/501, P 30 [POS] and PA 150) all grafted on a common rootstock over a 12-month period. To circumvent possible complications resulting from inter-species competition (as is the case typically under field conditions where other plants are used as shade for cacao) the experiment was conducted in a nursery environment using shade netting to vary the intensity of incident light.

MATERIALS AND METHODS

\section{Plant material}

Three cacao clones T 79/501, PA 150 and SCA 6, representing, respectively, a vigorous, an intermediate and a low vigour genotype, and P 30 [POS] (a traditionally cultivated cacao genotype in Ghana, used in this work as control) were propagated by side grafting using a common seedling rootstock (T 60/887 × Amelonado). Care was taken to insert the scion below the point of attachment of cotyledons of the rootstock to prevent chupons growing from below the graft union.

\section{Experimental design}

The experiment was conducted at the Cocoa Research Institute of Ghana, New Tafo, Eastern Region, Ghana. The experiment was designed as a split-plot with shade as the main plot factor and the four genotypes as sub-plots. There were five plants per sub-plot and each plot was replicated three times. Results were analysed (using Genstat) by analyses of variance, and significance among mean values was determined by least significant difference (LSD) values where $p=0.05$.

The experiment was conducted inside a $35 \mathrm{~m} \times 30-\mathrm{m}$ nursery shade house that was covered artificially on all sides with a single-layer of shade netting, supported by galvanized pipes and rafters. Shade levels were measured twice in each of the three seasons by means of a 'SunScan' System SS1 (Delta-T, UK). The experiment incorporated three shade regimes: 'light' (32.5\%), 'medium' (55\%) and 'heavy' (76\%) shades, created, respectively, by means of (i) the single layer of shade netting, (ii) the erection of an additional single-netted or (iii) double-netted cage over the growing areas.

Prior to imposition of the shade treatments, a drainage system was put into place. The plants were put into the treatments on 8 March 2007. Growing pots [black polythene bags $(32 \mathrm{~cm} \times 37.5 \mathrm{~cm})$, perforated with 28 evenly distributed holes $(0.7 \mathrm{~cm}$ in diameter) and filled with top-soil] were placed in pits on top of a layer of river sand. 
Each pot contained a young clonal cacao plant of one of the four cacao genotypes. More sand was added between the pots until the river sand layer was approximately 27-cm deep, leaving the top $15 \mathrm{~cm}$ of the pit empty. The perforations in the growing pots provided contact between the topsoil in the pots and the river sand in the pits, while the holes in the polythene sheet ensured drainage down the pit. Watering was not direct to the growing pots, but was applied to the river sand when its water content declined from field capacity.

\section{Photosynthesis and leaf chlorophyll fluorescence measurements}

Beginning in April 2007, a portable photosynthesis-measuring system incorporating an infrared gas analyzer (LCpro+, ADC Bioscience, UK) was used to measure photosynthesis once every month through the major rainy (April-July) and the minor rainy (August-October) seasons of 2007 and during the dry season (in November 2007 and January/February 2008) of the 2007-2008 crop year of Ghana. Measurements were carried out between 9:00 am and 11:00 am on three plants per treatment per block. A diurnal study was also carried out on 28 April 2008, in which an artificial light source provided a constant saturated light intensity $\left(1200 \mu \mathrm{mol}\right.$ photons $\mathrm{m}^{-2}$ $\mathrm{s}^{-1}$ ) to assess diurnal photosynthesis under constant light conditions. Measurements were carried out between 8:00 am and 4:00 pm.

Around midday on the same days that photosynthesis measurements were conducted, leaf chlorophyll fluorescence was measured using a leaf chlorophyll fluorescence meter (FP100; Photon Systems Instruments, the Czech Republic) on leaves that had been dark adapted for $30 \mathrm{~min}$. A set of diurnal leaf chlorophyll fluorescence measurements was conducted on 28 April 2008 between 8 am and 4 pm.

\section{Microclimate measurements}

Small data loggers (Tinytag, Gemini Data Loggers, Chichester, UK) placed in Stephenson screens were used to record the temperature and relative humidity at 15-min intervals in the three shade environments of the trial.

\section{Determination of leaf area and plant dry weight}

At the end of the experiment (in May 2008) two out of the three plants in each plot (=6 per treatment) that had been previously selected for photosynthesis measurements were harvested destructively to determine the leaf area (using an automatic leaf area meter, Delta-T Devices Ltd., Burwell, Cambridge, UK) and subsequently plant organ dry weight after drying at $80{ }^{\circ} \mathrm{C}$ for $60 \mathrm{~h}$ (using a ventilated drying oven, OV-165, Thermo Scientific, UK).

\section{RESULTS}

\section{Microclimatic data}

Table 1 summarises the temperature and relative humidity conditions recorded under the different shade regimes during the three seasons, and Table 2 summarises the mean sunshine hours across the seasons. 
Table 1. Mean seasonal relative humidity $(\mathrm{RH})$, temperature $(\mathrm{T})$ and vapour pressure deficit (VPD) under different shade regimes over the experimental period.

\begin{tabular}{|c|c|c|c|c|c|c|c|c|c|c|c|c|}
\hline \multirow{2}{*}{$\begin{array}{l}\text { Season } \\
\text { Shade } \\
\text { level }\end{array}$} & \multicolumn{3}{|c|}{ Major rainy season } & \multicolumn{3}{|c|}{ Minor rainy season } & \multicolumn{3}{|c|}{ Dry } & \multicolumn{3}{|c|}{ Mean } \\
\hline & $\begin{array}{l}\text { RH } \\
(\%)\end{array}$ & $\mathrm{T}\left({ }^{\circ} \mathrm{C}\right)$ & $\begin{array}{l}\text { VPD } \\
(\mathrm{kPa})\end{array}$ & $\begin{array}{l}\text { RH } \\
(\%)\end{array}$ & $\mathrm{T}\left({ }^{\circ} \mathrm{C}\right)$ & $\begin{array}{l}\text { VPD } \\
(\mathrm{kPa})\end{array}$ & $\begin{array}{l}\text { RH } \\
(\%)\end{array}$ & $\mathrm{T}\left({ }^{\circ} \mathrm{C}\right)$ & $\begin{array}{l}\text { VPD } \\
(\mathrm{kPa})\end{array}$ & $\begin{array}{l}\text { RH } \\
(\%)\end{array}$ & $\mathrm{T}\left({ }^{\circ} \mathrm{C}\right)$ & $\begin{array}{l}\text { VPD } \\
(\mathrm{kPa})\end{array}$ \\
\hline $32.5 \%$ & 70.0 & 36.9 & 1.9 & 64.9 & 31.9 & 1.7 & 50.2 & 36.8 & 3.1 & 61.7 & 35.2 & 2.2 \\
\hline $55 \%$ & 72.8 & 34.8 & 1.5 & 73.1 & 31.2 & 1.2 & 51.1 & 35.2 & 2.8 & 65.7 & 33.7 & 1.8 \\
\hline $76 \%$ & 75.0 & 32.2 & 1.2 & 76.8 & 31.0 & 1.0 & 58.5 & 33.3 & 2.1 & 70.1 & 32.2 & 1.4 \\
\hline Mean & 72.6 & 34.6 & 1.5 & 71.6 & 31.4 & 1.3 & 53.3 & 35.1 & 2.7 & 65.8 & 32.7 & 1.8 \\
\hline
\end{tabular}

Table 2. Mean seasonal sunshine hours over the experimental period.

\begin{tabular}{ccccc}
\hline & Major rainy season & Minor rainy season & Dry season & Mean \\
\hline Mean sunshine hours & 5.2 & 4.4 & 6.7 & 5.4 \\
\hline
\end{tabular}

As a result of overcast conditions that characterised much of the minor rainy season (Table 2), mean aerial temperatures were approximately $3.3^{\circ} \mathrm{C}$ lower during the minor rainy season compared with the major rainy season and $3.8^{\circ} \mathrm{C}$ lower than during the dry season. Also, mean temperature under the heavy shade was approximately $3{ }^{\circ} \mathrm{C}$ lower than under the light shade treatment (Table 1).

The mean relative humidity averaged over two rainy seasons was $72.1 \%$ compared with a mean value of $53.3 \%$ for the dry season. The mean relative humidity under heavy shade was $70.1 \%$ compared with $61.7 \%$ under light shade (Table 1). Vapour pressure deficit was lower during the rainy seasons than during the dry season, the difference being the greatest under the light shade regime.

\section{Seasonal variation in stomatal conductance}

There was a significant $(p<0.001)$ season $\times$ shade interaction on stomatal conductance. During the dry season, plants under heavy shade had higher stomatal conductance. In contrast, in the rainy seasons, heavily shaded plants had lower stomatal conductance rates compared with plants under lighter shade. Over the entire experimental period, differences in stomatal conductance between cacao clones were not significant. However, a significant $(p<0.001)$ season $\times$ clone interaction was observed. While all the clones had lower stomatal conductance rates in the dry season than in the rainy seasons, the difference was more pronounced for the clone PA 150 (Figure 1).

\section{Seasonal variation in photosynthesis}

Similar to the observation in stomatal conductance, there was a seasonal influence on photosynthetic rate $(p<0.001)$. The response to shade treatments varied between seasons, hence the season $\times$ shade interaction was significant $(p<0.001)$. The lowest rates were recorded in the dry season, in which little variation was observed between shade treatments (Figure 2). In that season, plants under medium shade had the 


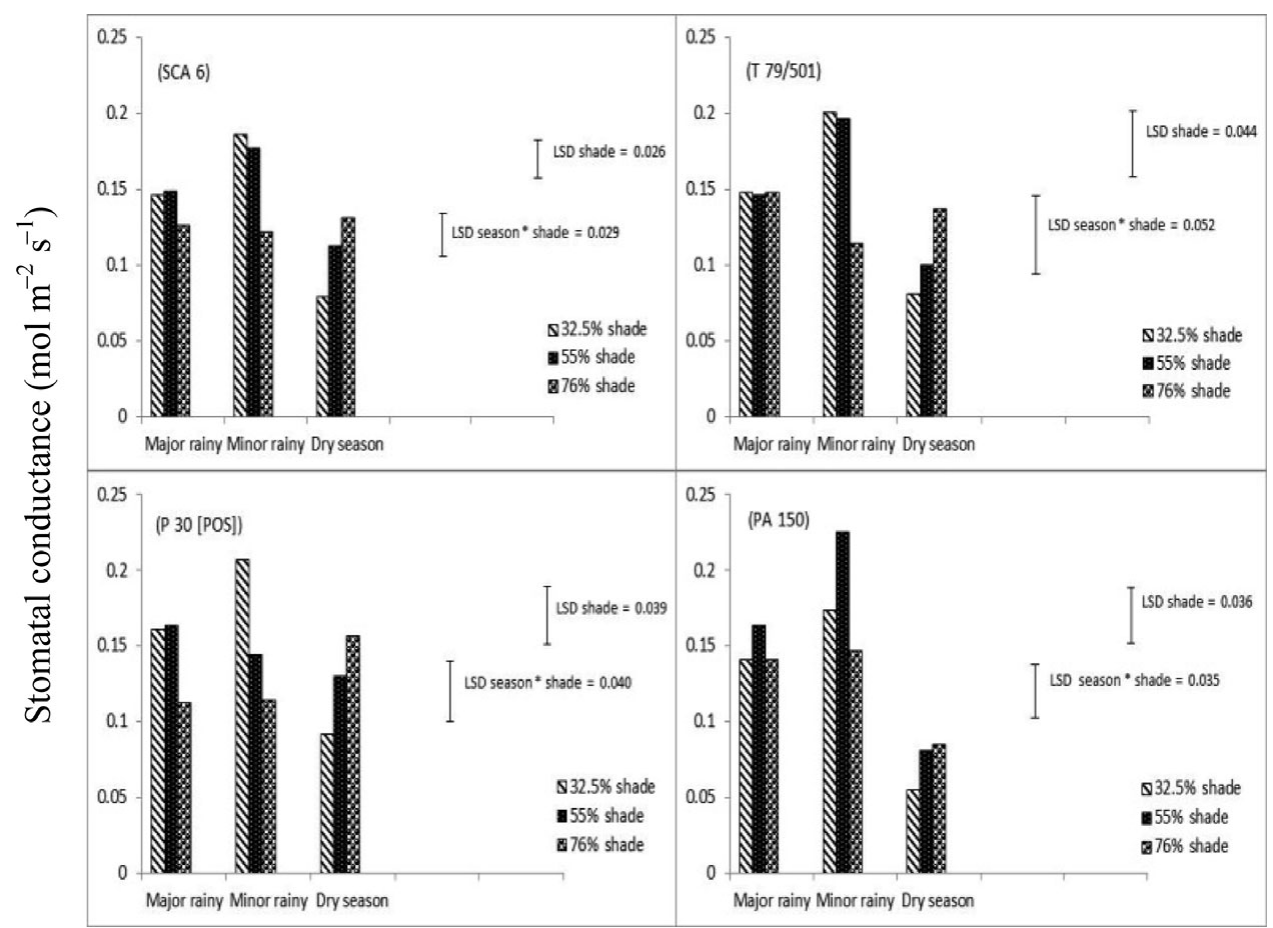

Figure 1. Stomatal conductance of cacao under varying shade and in different seasons. (Each bar represents the mean of four measurements on nine plants per treatment).

highest photosynthetic rates (mean $=0.82 \mu \mathrm{mol} \mathrm{CO}_{2} \mathrm{~m}^{-2} \mathrm{~s}^{-1}$ ), while those under light shade had the lowest photosynthetic rates $\left(\right.$ mean $=0.50 \mu \mathrm{mol} \mathrm{CO}_{2} \mathrm{~m}^{-2} \mathrm{~s}^{-1}$ ). Photosynthetic rates were higher in the rainy seasons compared with the dry season. In the rainy seasons photosynthesis was the highest under light shade and the lowest under heavy shade. The average photosynthetic rates under light, medium and heavy shade treatments were 3.3, 1.6 and $1.2 \mu \mathrm{mol} \mathrm{CO} \mathrm{Cm}^{-2} \mathrm{~s}^{-1}$, respectively, in the minor rainy season, and 6.0, 3.0 and $1.1 \mu \mathrm{mol} \mathrm{CO}_{2} \mathrm{~m}^{-2} \mathrm{~s}^{-1}$, respectively, in the major rainy season. Variation in photosynthesis between shade treatments was consistent across all genotypes with no significant differences between genotypes (Figure 2).

\section{Diurnal pattern of photosynthesis}

Photosynthetic rates were significantly higher $(p=0.004)$ during the first half of the day (between 8:00 am and 12:00 noon) than during the second half. The highest rates of photosynthesis were recorded between 10:00 am and 12:00 noon, after which the rates declined steadily until the end of the day (Figure 3). Photosynthetic rates declined with increasing shade intensity $(p<0.001)$. There was no interaction between time of day and shade level on diurnal pattern of photosynthesis. There was also no significant difference in photosynthetic rates between the cacao genotypes throughout the course of the day. 


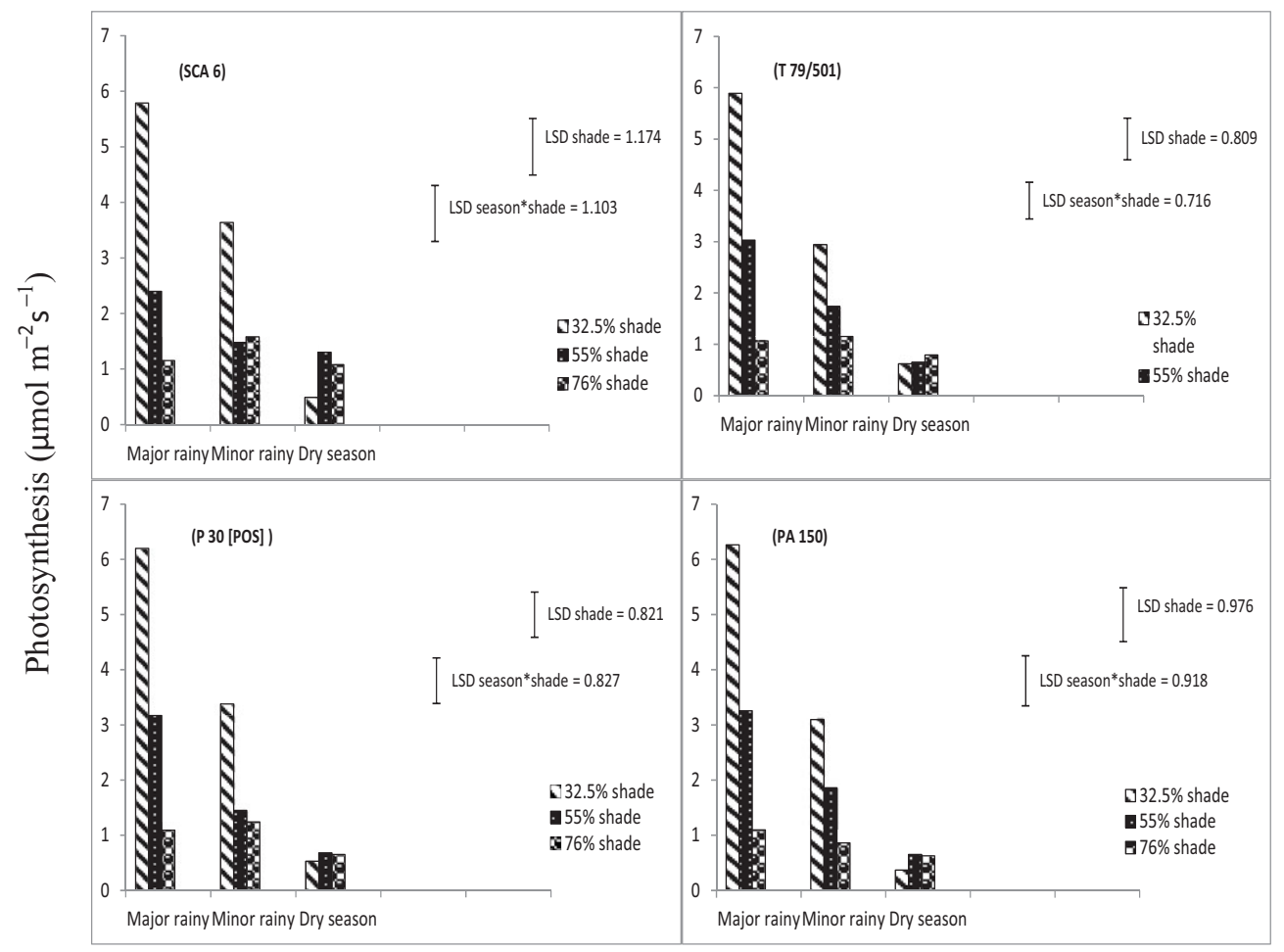

Figure 2. Photosynthesis of cacao under varying shade and in different seasons. (Each bar represents the mean of four measurements on nine plants per treatment).

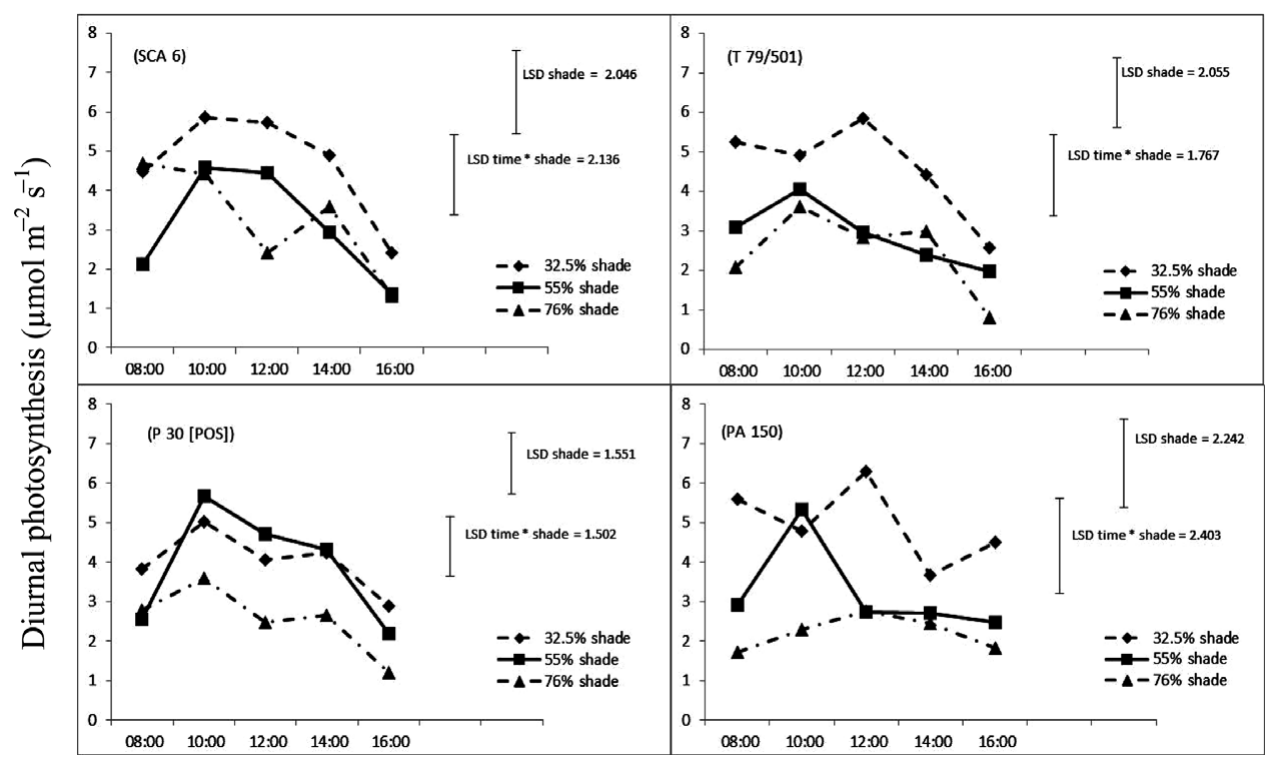

Figure 3. Diurnal pattern of photosynthesis of cacao under different shade levels. (Each line represents the mean for nine plants per shade treatment). 


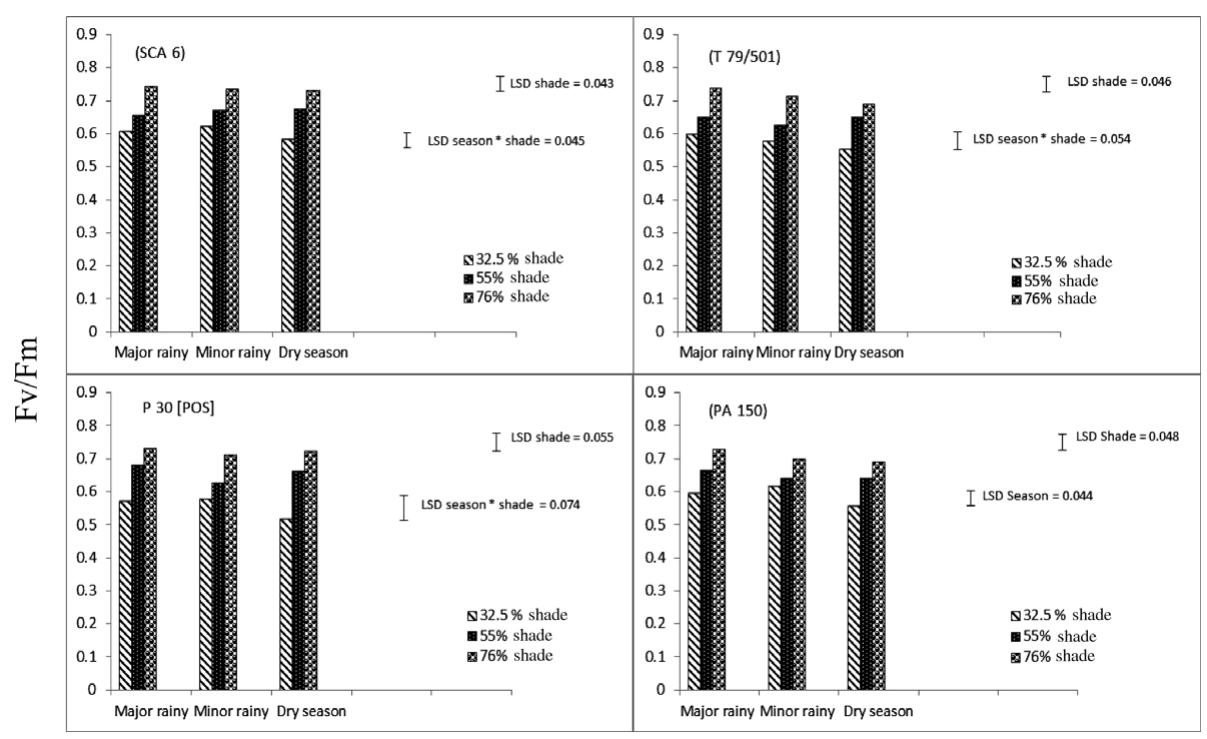

Figure 4. Leaf chlorophyll fluorescence of cacao under different shade levels. (Each bar represents the mean of four measurements on nine plants per shade treatment).

\section{Seasonal variation in leaf chlorophyll fuorescence}

Variable $(\mathrm{Fv})$ /maximum $(\mathrm{Fm})$ fluorescence values increased with greater shade level through all seasons $(p<0.001)$. Also, there was a slight reduction in $\mathrm{Fv}_{\mathrm{V}} / \mathrm{Fm}$ during the dry season, which was more pronounced under the light shade treatment. Thus, the season $\times$ shade interaction was significant $(p=0.013)$. Small but significant $(p=0.006)$ differences were observed between the cacao genotypes in their Fv/Fm values, which were consistent between shade levels and between seasons (Figure 4). The respective Fv/Fm ratios for T 79/501, P 30 [POS], PA 150 and SCA 6 were 0.643, 0.644, 0.648 and 0.669 respectively.

\section{Diurnal pattern of chlorophyll fluorescence}

Values of $\mathrm{F}_{\mathrm{V}} / \mathrm{Fm}$ measured over a single day declined towards the mid part of the day and then increased during the second half of the day $(p=0.001)$. It was also consistently higher $(p<0.001)$ under heavier shade (Figure 5$)$ although the nature of the response to shade differed between clones. Differences between the clones were significant $(p<0.001)$, varying from 0.650 for PA 150 to 0.679 for $\mathrm{T} 79 / 501$. Whereas the time $\times$ clone interaction was not significant, the shade $\times$ clone interaction was significant $(p<0.001)$, reflecting the fact that suppression of $\mathrm{F}_{\mathrm{V}} / \mathrm{Fm}$ under higher light conditions was greater for some clones (e.g. SCA 6) than others.

\section{Leaf production}

Plants under heavy shade produced the lowest final leaf area per plant (Figure 6). The shade $\times$ genotype interaction was significant $(p<0.04)$ such 


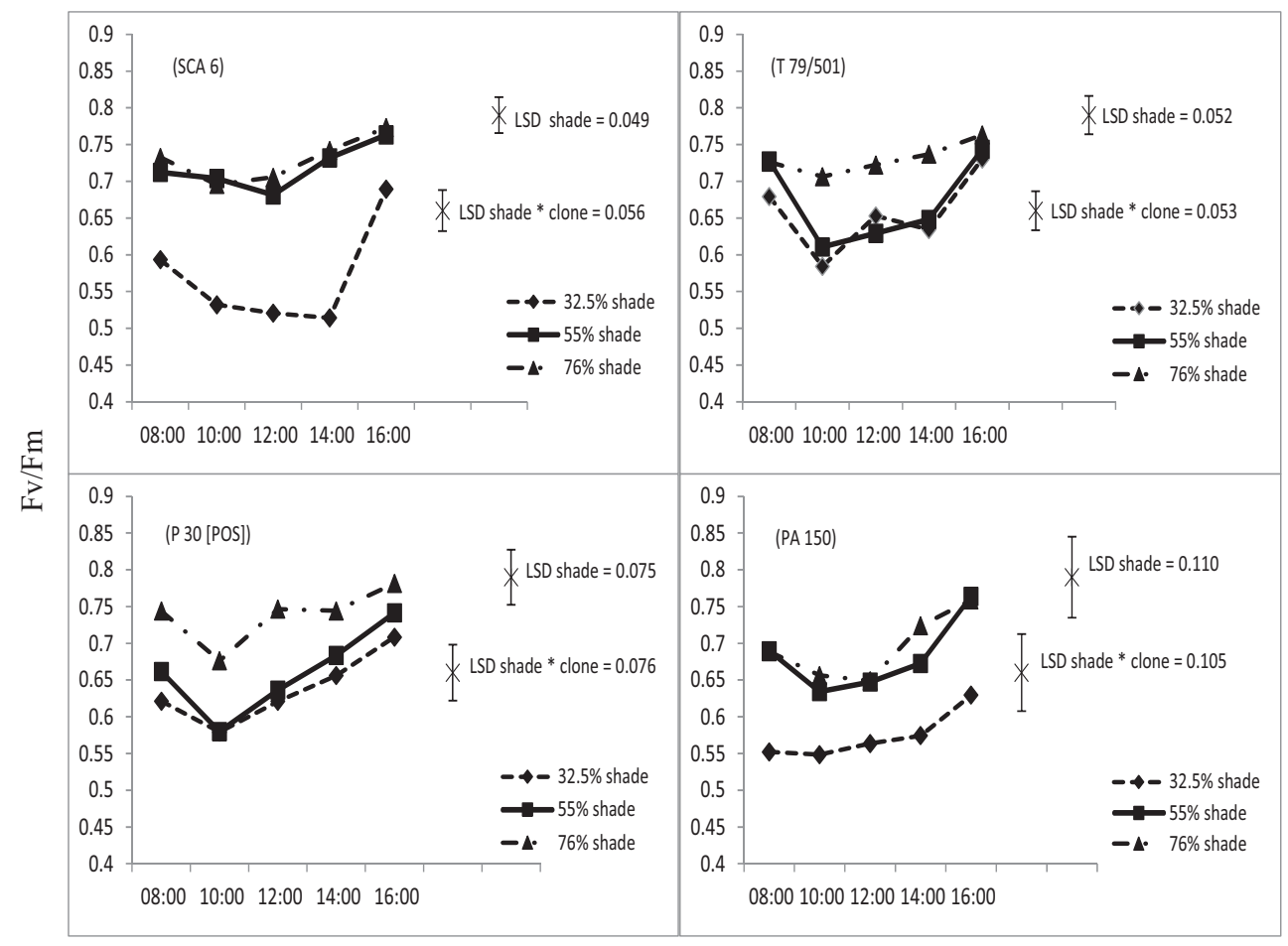

Figure 5. Diurnal pattern of leaf chlorophyll fluorescence of cacao under varying shade. (Each line represents the mean for nine plants per shade treatment).

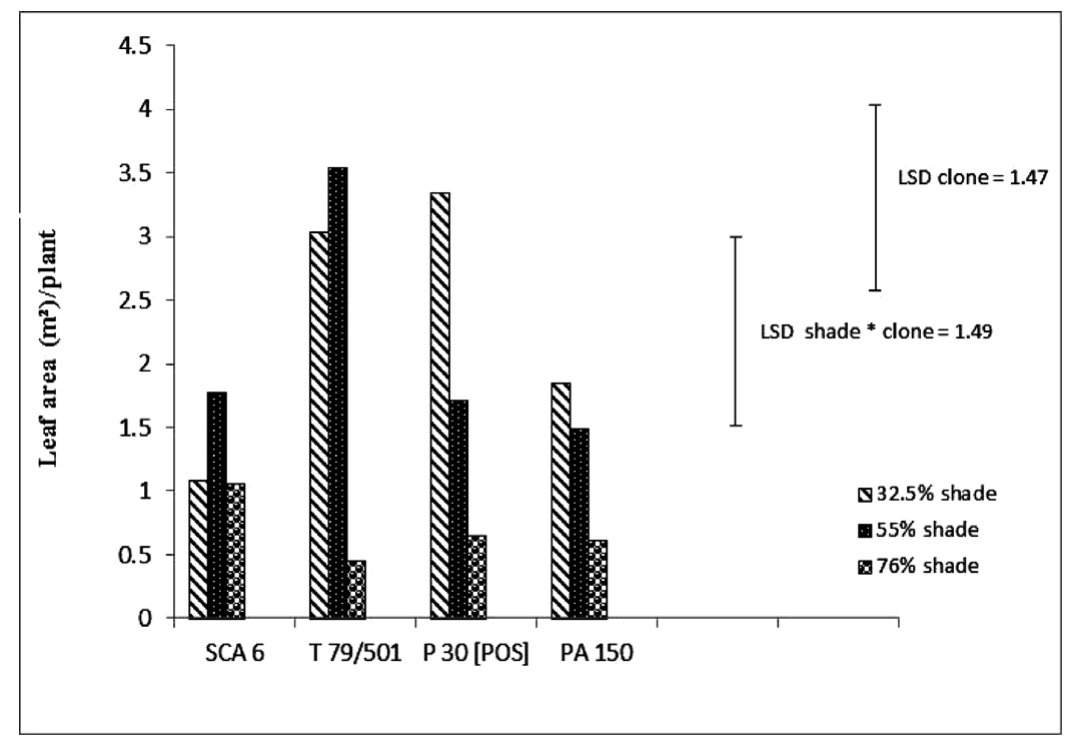

Figure 6. Final leaf area per plant under different shade levels. (Each bar represents the mean value for six plants per treatment). 


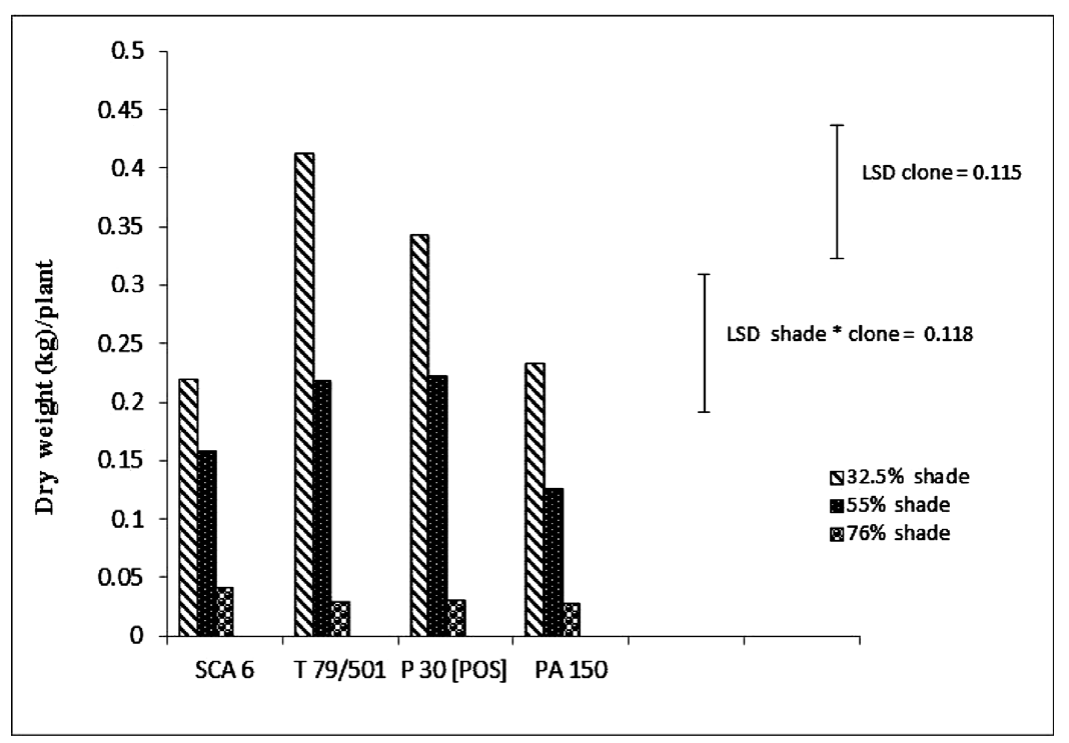

Figure 7. Mean final stem dry weight of cacao under different shade levels. (Each bar represents the mean dry weight of six plants per treatment).

that SCA 6 and T 79/501 gave the highest leaf areas under the medium shade, while P 30 [POS] and PA 150 gave the highest leaf areas under the light shade treatment.

\section{Stem dry weight}

For all genotypes, stem dry matter accumulation was significantly $(p=0.003)$ lower under increasing shade. The response to shade differed between clones, it being the greatest for clone T 79/501 and the least for SCA 6 (Figure 7).

\section{DISCUSSION}

Photosynthetic rates were the highest under light shade in the rainy seasons for all four genotypes studied. During the dry season, however, photosynthetic rates were much lower and the differences between treatments were smaller, the trend being opposite to that seen in the wet seasons, i.e. rates were generally higher under heavier shade. Since soil water was not limiting in this experiment, the seasonal variation in photosynthetic rate was most likely modulated by changes in vapour pressure deficit. Previous studies have shown that stomatal conductance in cacao is limited by vapour pressure deficit above a particular threshold (Raja Harun and Hardwick, 1988a; Sena Gomes et al., 1987). Therefore, during the rainy seasons when vapour pressure deficit would not severely limit stomatal opening, light was the main limiting factor (light levels are typically lower in the minor rainy seasons, hence the lower photosynthetic rates observed). In contrast, during the dry season, vapour pressure deficit appeared to be a limiting factor, particularly for plants grown under the low shade (high light) treatment. Thus, the ameliorating effects of higher shade in the dry season (resulting 
in a slightly lower vapour pressure deficit) resulted in a higher photosynthetic rate under this treatment.

Some evidence for photoinhibition was observed as Fv/Fm values were lower under higher light conditions. However, this photoinhibition was not so significant as to prevent the highest photosynthetic rate being expressed under the light shade regime during the wet seasons. In the dry season the difference between shade treatments was slightly greater, presumably due to the fact that ambient light levels were higher at this time of the year.

There was an evidence for photoinhibition from the diurnal chlorophyll fluorescence measurements typically from late morning until afternoon. This was especially the case under low shade conditions and was consistent with the observations of Serrano and Biehl (1996). By the end of the day, Fv/Fm values had typically recovered to, or were higher than early morning values, suggesting that the photoinhibition observed was partially reversible. Nevertheless, for all four clones, values of $\mathrm{Fv}_{\mathrm{V}} / \mathrm{Fm}$ remained lower under the high light conditions at both beginning and end of the day, implying that non-reversible inhibition was also present. The results also imply that in terms of photoinhibition clones SCA 6 and PA 150 were the most sensitive to high light intensities.

When considering net assimilation over the course of a day, although a constant saturating irradiance was applied, photosynthetic rates varied through time with higher rates occurring in the morning than in the afternoon. This was observed in spite of the fact that for most treatments $\mathrm{FV}_{\mathrm{V}} / \mathrm{Fm}$ recovered through the course of the afternoon. Since vapour pressure deficits are typically higher in the afternoon, this may have been the cause of the reduction in photosynthetic rate. Previous studies have suggested that even in the case of mature cacao, some overhead shade should be provided, otherwise the photosynthetic rate of cacao is likely to decrease (Galyuon et al., 1996b; Hutcheon, 1981; Raja Harun and Hardwick, 1988b). While this is a factor to consider in shading, the results of the present study suggest that the amelioration of high vapour pressure deficit is also a major consideration.

The larger leaf area observed with increasing light is not only reflective of higher photosynthetic rates but also implies that there was no greater leaf abscission under high light as earlier observed by Ofori-Frimpong et al. (2007). Genotypic differences in leaf area under the different shade levels suggest differential partitioning of assimilates in response to light. This differential partitioning was probably the main factor underlying the different magnitudes of response to shade in terms of final biomass between the four cacao clones studied. Furthermore, since there were no big differences in photosynthetic rates between genotypes, the differential partitioning of assimilate to the leaf component was an important factor in the observed overall genotypic difference in biomass.

The observation that both season and time of the day influence the photosynthetic performance of cacao under different light regimes may explain the considerable inconsistency observed in what is regarded as the optimal shade level for the growth of cacao. The fact that over the entire period, plants under light shade had photosynthetic rates that were over three times faster than those under the heavy shade treatment 
(which was also reflected in the plants' growth) demonstrates that, with enough soil water and in the absence of severe mirid infestations (Babin et al., 2010), young cacao can be grown under less shade than has been generally been recommended (usually around 50\% shade; Opoku-Ameyaw et al., 2010).

The use of overhead shade may, nevertheless, be used by the farmer for other reasons, such as provision of an alternate crop or aiding in pest control. This study has demonstrated genotypic differences in early growth under shade and therefore some genotypes are likely to be more suited than others to growth under shade. This work has also shown that for young cacao, shade should be provided on the basis of the current ambient environment and that good shade management needs to take into account changes in the aerial environment from wet season to dry season.

Acknowledgements. The authors are grateful to Patricia Adu-Yeboah, Hakeem Rashied and Godwin Addo of the Cocoa Research Institute of Ghana (CRIG) for providing technical support. The authors are grateful to the Cocoa Research Association, the CFC and the Ghana COCOBOD for part-funding this work. This paper is published with the kind permission of the Executive Director of CRIG.

\section{REFERENCES}

Ahenkorah, Y., Akrofi, G. and Adri, A. K. (1974). The end of the first shade and manurial experiment at the Cocoa Research Institute of Ghana. Fournal of Horticultural Science 49:43-49.

Babin, R., Gerben, M., Hoopen, T., Cilas, C., Enjalric, F., Yede, Gendre, P. and Lumaret, J. (2010). Impact of shade on the spatial distribution of Sahlbergella singularis in traditional cocoa agroforests. Agricultural and Forest Entomology 12:69-79.

Da Matta, F. M., Loos, R. A., Rodrigues, R. and Barros, R. S. (2001). Actual and potential photosynthetic rates of tropical crop species. Revista Brasileira de Fisiologia Vegetal 13:24-32.

Daymond, A. J., Tricker, P. J. and Hadley, P. (2011). Genotypic variation in photosynthesis in cacao is correlated with stomatal conductance and leaf nitrogen. Biologia Plantarum 55:99-104.

de Almeida, A.-A. F. D. and Valle, R. R. (2007). Ecophysiology of the cacao tree. Brazilian Fournal of Plant Physiology 19:425-448.

Galyuon, I. K. A., Mcdavid, C. R., Lopez, F. B. and Spence, J. A. (1996a). The effect of irradiance level on cocoa (Theobroma cacao L.): I. Growth and leaf adaptations. Tropical Agriculture (Trinidad) 73:23-28.

Galyuon, I. K. A., Mcdavid, C. R., Lopez, F. B. and Spence, J. A. (1996b). The effect of irridiance level on cacao (Theobroma cacao L.): II. Gas exchange and chlorophyll fluorescence. Tropical Agriculture (Trinidad) 73:29-33.

Hutcheon, W. V. (1981). Physiological Studies on Cacao (Theobroma cacao) in Ghana, Ph.D thesis, University of Aberdeen, United Kingdom.

International Cocoa Organization (ICCO) (2008). Annual Forecasts of Production and Consumption and Estimates of Production Levels to Achieve Equilibrium in the World Cocoa Market. Annual Report. Berlin, Germany: ICCO.

Ofori-Frimpong, K., Asase, A. and Yelibora, M. A. (2007). Cocoa Farming and Biodiversity in Ghana. Annual Report, EarthWatch Institute. Boston, MA: EarthWatch Institute.

Opoku-Ameyaw, K., Baah, F., Gyedu-Akoto, E. and Anchirina, V. (2010). Shade Management. New Tafo Akim, Ghana: Cocoa Research Institute of Ghana.

Rada, F., Jaimez, R. E., Garcia- Nunez, C., Azocar, A. and Ramirez, M. E. (2005). Water relations and gas exchange in Theobroma cacao var. Guasare under periods of water deficits. Revista de la Facultad de Agronomia (LUZ) 22:105-112.

Raja Harun, R. M. and Hardwick, K. (1988a). The effect of different temperatures and water vapour pressure deficits on photosynthesis and transpiration of cacao leaves. In 10th International Cocoa Research Conference, Santo Domingo, Dominican Republic, 17-23 May 1987, 211-214. 
Raja Harun, R. M. and Hardwick, K. (1988b). The effects of prolonged exposure to different light intensities on the photosynthesis of cacao leaves. In 10th International Cocoa Research Conference, Santo Domingo, Dominican Republic, 17-23 May 1987, 205-209.

Sena Gomes, A. R., Kozlowski, T. T. and Reich, P. B. (1987). Some physiological responses of Theobroma cacao var. catongo seedlings to air humidity. New Phytologist 107:591-602.

Serrano, P. and Biehl, B. (1996). Light stress on cacao (Theobroma cacao L.) fluorometric measurements under different light conditions in the field. In 12th International Cocoa Research Conference, Salvador, Bahia, Brazil, 17-23 November 1996, 583-588. 